\title{
Comparative calculation of piles taking into account seismic impacts (example in Ho Chi Minh City)
}

\author{
Vitalii Sidorov, Duc Anh Le", Evgeny Sobolev \\ Moscow State University of Civil Engineering, Yaroslavskoe shosse, 26, Moscow, 129337, Russia
}

\begin{abstract}
The construction of high-rise building and structures has been widely developed recently in Vietnam. Pile foundations are considered one of the most suitable solutions when choosing the foundations for their construction, especially in difficult geological conditions, including seismic areas. According to many researches, geological conditions of Ho Chi Minh City are generally difficult. The occurrence of earthquakes there influences the conditions for the construction. Besides, many historical cases have shown that soil liquefaction is often manifested, negatively affecting the underground structures and foundation working.

With an increase in investments of international construction companies and organizations in Vietnam, pile foundations can be designed according to domestic or foreign normative documents. Therefore, at present, a better understanding and detailed analysis of various existing normative documents and methods for designing pile foundations are required, especially when the influence of soil liquefaction is taken into account. This paper presents a review of various normative documents, including Russian, Vietnamese, American and Eurocode. The different methods in these normative documents for calculating the piles' bearing capacity are considered in 2 cases: with and without taking into account the soil liquefaction based on the hypothesis that the additional downward loads due to self-compaction of liquefiable soils affect piles. Finally, a comparison of the calculation results is presented. The comparison shows how these considering methods in these normative documents differ from each other and how much the pile's bearing capacity can be reduced when considering the soil liquefaction in calculations.
\end{abstract}

\section{Introduction}

Recently, the construction of high-rise buildings and structures has been widely developed in the world. In particular, in Vietnam, a qualitative analysis and selection of the type of foundations for those buildings and structures are also required, ensuring operational reliability and cost-effectiveness. One of the most suitable solutions when choosing the type of foundations for the construction of heavy buildings and structures is a pile foundation,

*Corresponding author: ducanh.mtak49@gmail.com 
especially in difficult geological conditions, for example, when building in seismic regions. [1-3].

Vietnam is located in the Asia-Pacific region on the Pacific Ring of Fire, where many earthquakes occur. Geotechnical conditions in Vietnam are generally difficult, including in Ho Chi Minh City. According to a lot of researches, the territory of Ho Chi Minh City is covered with a variety of weak soils, such as fluid-plastic silts and clays. The thickness of the layers of these weak soils is significant; for example, the thickness of the silt layer is more than $15 \mathrm{~m}$, as a result of which the use of shallow foundations is limited or completely impossible. Then, under the influence of a weak seismic effect on the base and foundations, the destruction of buildings and structures is possible. Therefore, it is necessary to consider the effects of seismic loads and secondary processes after earthquakes when designing pile foundations.

Historical cases have shown that after seismic impacts in water-saturated soils, such processes as soil liquefaction are often manifested, which negatively affects the foundation and foundations' working [4-6]. The existing concept of the cause and the liquefaction process has been introduced to a number of studies by domestic and foreign scientists [712]. Cosidering the influence of soil liquefaction on the working of pile foundations, the authors also propose a hypothesis about the manifestation of additional negative loads within the liquefied stratum, which is described in $[13,14]$.

\section{Materials and Methods}

For the first group of limit states, it is necessary to carry out calculations for the strength of the pile material, bearing capacity, and the loss of the foundation's overall stability for the design of pile foundations. In this work, only the calculation of friction piles by bearing capacity is considered. This calculation will be carried out using engineering methods set out in various existing normative documents, including Russian [15,16], Vietnamese [17,18], American standards [19] and Eurocode [20-22], in 2 design cases: with and without taking into account the influence of soil liquefaction.

\subsection{Methods for calculating piles under seismic effects without taking into account the influence of soil liquefaction}

\subsubsection{According to Russian normative documents}

In Russian normative documents, the basics for calculating the bearing capacity of piles under seismic effects are described in SP 24.13330.2011 [15], SP 14.13330.2018 [16]. The difference between the calculation without and when taking into account seismic effects is application decreasing coefficients $\gamma_{e q 1}$ and $\gamma_{e q 2}$. The formula for determining the bearing capacity of piles can be described by the formula (1):

$$
F_{d}=\gamma_{c}\left(\gamma_{R, R} \cdot \gamma_{e q 1} \cdot R \cdot A+u \cdot \sum \gamma_{R, f} \cdot \gamma_{e q 2} \cdot f_{i} \cdot h_{i}\right)
$$

where $\gamma_{c}$ - the pile working conditions coefficient; $\gamma_{R, R}-$ the working conditions coefficient of the soil at the pile tip; $R$ - the design resistance of the soil at the pile tip, $\mathrm{kPa}$; $A$ - the cross-section area of the pile, $\mathrm{m}^{2} ; u$ - the cross-sectional perimeter of the pile, $\mathrm{m}$; $\gamma_{R, f}$ - the pile shaft working conditions coefficient; $f_{i}$ - the design frictional resistance of the $i$-th soil layer, $\mathrm{kPa} ; h_{i}$ - the thickness of the $i$-th soil layer, $\mathrm{m}$. 
The design frictional resistance along the lateral surface of the pile $f_{i}$ is not taken into account in the value of the total bearing capacity to the depth $h_{d}$, which is determined by the formula (2):

$$
h_{d}=\frac{a_{1}\left(H+\alpha_{\varepsilon} a_{3} M\right)}{b_{p}\left(\frac{a_{2}}{\alpha_{\varepsilon}} \gamma_{I} \operatorname{tg} \varphi_{I}+c_{I}\right)} \leq \frac{3}{\alpha_{\varepsilon}}
$$

where: $a_{1}, a_{2}, a_{3}$ - dimensionless coefficients, taken depending on the type of pile foundations; Н и $\mathrm{M}$ - correspondingly, the value of horizontal force, $\mathrm{kN}$, and bending moment, kN.m; $\alpha_{\varepsilon}$ - the coefficient of deformation; $b_{p}$ - the conventional width of the pile; $\gamma_{I}$ - the value of the specific gravity of the soil determined taking into account the weighing effect of water for water-saturated soils, $\mathrm{kN} / \mathrm{m}^{3} ; \varphi_{I}$ и $c_{I}$ - correspondingly, the friction angle, degrees, and the cohesion of the soil, $\mathrm{kPa}$.

The value of the coefficient of deformation $\alpha_{\varepsilon}$ is determined by the formula (3):

$$
\alpha_{\varepsilon}=\sqrt[5]{\frac{K \cdot b_{p}}{\gamma_{c} \cdot E I}}
$$

\subsubsection{According to Vietnamese normative documents}

According to clause 12.3 of TCVN 10304:2014 [17], the bearing capacity of piles is determined taking into account the effects of seismic loads according to the following formula (4):

$$
R_{c, u}=\gamma_{c}\left(\gamma_{c q} \cdot \gamma_{e q 1} \cdot q_{b} \cdot A_{b}+u \cdot \sum \gamma_{c f} \cdot \gamma_{e q 2} \cdot f_{i} \cdot l_{i}\right)
$$

where $\gamma_{c q}$ - the pile toe working conditions coefficient; $q_{b}$ - the design resistance of the soil at the pile tip, $\mathrm{kPa} ; A_{b}$ - the cross-section area of the pile, $\mathrm{m}^{2}, u$ - the cross-sectional perimeter of the pile, $\mathrm{m} ; \gamma_{c f}$ - the pile shaft working conditions coefficient; $f_{i}$ - the design frictional resistance of the $i$-th soil layer, $\mathrm{kPa} ; l_{i}-$ the thickness of the $i$-th soil layer, $\mathrm{m}$.

The value of decreasing coefficients $\gamma_{e q 1}$ and $\gamma_{\text {eq } 2}$ is determined depending on the type of soil and the design seismicity, according to [17].

The design frictional resistance of piles is also taken to be 0 up to the design depth $h_{d}$, which is similarly determined according to indications in SP by formulas (2) and (3).

\subsubsection{According to Eurocodes}

When static loads are applied to the pile foundation, three approaches to designing a pile foundation are used in Eurocode 7, which differ from each other by entering partial resistance factors: Design Approach 1 (DA-1): A1 “+” M1 “+” R1 (combination 1) or A2 “+” M1 “+” R4 (combination 2); Design Approach 2 (DA-2): A1 “+” M1 “+” R2; Design Approach 3 (DA-3): A1 “+” M2 “+” R3. The recommended values of partial resistance factors corresponding to the combination of design approaches are given in the annex A [20].

The design bearing capacity of the pile can be defined by the formula (5):

$$
R_{c, d}=R_{b, d}+R_{s, d}=\frac{R_{b, k}}{\gamma_{b}}+\frac{R_{s, k}}{\gamma_{s}}
$$


In Eurocode 7, the characteristic values $R_{b, k}$ and $R_{s, k}$ shall either be determined by the formula (6):

$$
R_{c, k}=R_{b, k}+R_{s, k}=\frac{R_{b, c a l}+R_{s, c a l}}{\xi}=\frac{R_{c, c a l}}{\xi}=\min \left\{\frac{\left(R_{c, c a l}\right)_{\text {mean }}}{\xi_{3}} ; \frac{\left(R_{c, c a l}\right)_{\min }}{\xi_{4}}\right\}
$$

where $\xi_{3}$ и $\xi_{4}$ - correlation factors;

or by the method given below by the formula (7):

$$
\begin{aligned}
& R_{b, k}=A_{b} \cdot q_{b, k} \\
& R_{s, k}=\sum_{i} A_{s, i} \cdot q_{s, i, k}
\end{aligned}
$$

where $q_{b, k}, q_{s, i, k}$ - characteristic values of base resistance and shaft friction.

Both of the above procedures can be applied with design approaches DA-1 и DA-2. If DA-3 is used, the design value $X_{d}$ shall be defined by the formula (8):

$$
X_{d}=\frac{X_{k}}{\gamma_{m}}
$$

where $\gamma_{m}$ - the partial factor for soil parameters.

\subsubsection{According to American normative documents}

According to AASHTO LRFD BRIDGE 2017 [19], the bearing capacity of a single pile can be determined by the formula (9):

$$
\begin{aligned}
& R_{R}=\varphi R_{n}=\varphi_{q p} \cdot R_{p}+\varphi_{q s} \cdot R_{s} \\
& R_{p}=q_{p} \cdot A_{p} ; R_{s}=q_{s} \cdot A_{s}
\end{aligned}
$$

where $R_{p}$ - nominal shaft tip resistance, kips ( $\left.1 \mathrm{kips}=4,45 \mathrm{kN}\right) ; R_{s}$ - nominal shaft side resistance, kips; $\varphi_{q p}, \varphi_{q s}$ - resistance factors for tip and shaft side resistance; $q_{p}, q_{s}$ - unit tip resistance and side resistance, $\mathrm{ksf}(1 \mathrm{ksf}=47,88 \mathrm{kPa}) ; A_{p}, A_{s}$ - area of shaft tip and shaft side surface, $\mathrm{ft}^{2}\left(1 \mathrm{ft}^{2}=0,093 \mathrm{~m}^{2}\right)$.

In the case of cohesive soils, pile foundations are designed using total and effective stress methods. The unit side resistance $q_{s}$ is taken equal to 0 in the limit of $1.5 \mathrm{~m}$ from the pile head, and is determined by the formula (10):

$$
q_{s}=\alpha \cdot S_{u}
$$

in which the value of $\alpha$ is defined according to (11):

$$
\begin{aligned}
& \alpha=0,55 \text { for } \frac{S_{u}}{p_{a}} \leq 1,5 \\
& \alpha=0,55-0,1\left(\frac{S_{u}}{p_{a}}-1,5\right) \text { for } 1,5 \leq \frac{S_{u}}{p_{a}} \leq 2,5
\end{aligned}
$$

где: $S_{u}$ - undrained shear strength, ksf; $\alpha$ - adhesion factor; $p_{a}$-atmospheric pressure.

The nominal unit tip resistance of the pile $q_{p}$ shall be taken by the formula (12):

$$
q_{p}=N_{c} \cdot S_{u} \leq 80 \mathrm{ksf}
$$

in which the value of $N_{c}$ is defined according to (13):

$$
N_{c}=6\left[1+0,2\left(\frac{Z}{D}\right)\right] \leq 9
$$


where $D$ - diameter of pile, $\mathrm{ft} ; Z$ - penetration of pile, $\mathrm{ft}$.

In cohesionless soils, piles should be designed by effective stress methods for drained loading conditions or by empirical methods. The unit side resistance is determined by the formula (14):

$$
q_{s}=\beta \cdot \sigma_{v}^{\prime}
$$

in which the value of $\beta$ is defined according to (15):

$$
\beta=\left(1-\sin \varphi_{f}^{\prime}\right)\left(\frac{\sigma_{p}^{\prime}}{\sigma_{v}^{\prime}}\right)^{\sin \varphi_{f}^{\prime}} \cdot \tan \varphi_{f}^{\prime}
$$

where $\beta$ - load transfer coefficient; $\varphi_{f}^{\prime}$ - the friction angle of soil, град.; $\sigma_{p}^{\prime}$ - effective vertical preconsolidation stress; $\sigma_{v}^{\prime}$ - vertical effective stress at soil layer mid-depth.

The correlation for effective soil friction angle shall be taken by formula (16):

$$
\varphi_{f}^{\prime}=27,5+9,2 \log \left[\left(N_{1}\right)_{60}\right]
$$

where $\left(N_{1}\right)_{60}$ - SPT $N$-value corrected for effective overburden stress.

The value of the effective vertical pre-consolidation stress can be approximated depending on SPT $N_{60}$-value.

When designing pile foundations in seismic areas, the pile's bearing capacity is determined similarly to the case of the effect of static loads, only using the value of all resistance factors equal to 1.0. Determination of the depth of a possible liquefied soil stratum is described in paragraph 3.11.8 [19].

\subsection{Methods for calculating piles under seismic effects taking into account the influence of soil liquefaction}

In this section, the influence of soil liquefaction on the bearing capacity of a pile is considered, based on the hypothesis that additional negative friction along the lateral surface of the pile occurs in the liquefied soil.

\subsubsection{According to Russian normative documents}

In SP 24.13330.2011, indications of taking into account the influence of soil liquefaction on the pile's bearing capacity are not provided. Based on the above hypothesis, it is proposed to take into account the manifestation of negative loads $P_{n}$ to the depth $h_{d}$, the value of which, according to clause 9.10 [16], is determined by the formula (17):

$$
P_{n}=u \sum_{0}^{h_{d}} \tau_{i} h_{i}
$$

in which $\tau_{i}$ - unit negative frictional resistance, defined by (18):

$$
\tau_{i}=\varsigma \sigma_{z g} \tan \varphi_{I}+c_{I} ; \varsigma=\left(\frac{n_{\max }}{n_{i}}\right)\left(1+\frac{H_{i}}{H_{0}}\right)^{-0.5}
$$

where $\varsigma$ - experimental parameter characterizing the lateral pressure at the contact boundary between the pile and the soil; $n_{\max }$ - the maximum value of the porosity of the liquefied soil; $n_{i}$ - porosity of $i$-th soil layer; $H_{i}$ - the mid-depth of $i$-th soil layer; $H_{0}=1 \mathrm{~m}$; $\sigma_{z g}$ - vertical stress due to own weight; $\varphi_{I}, c_{I}$ - strength properties of the soil.

The formula for determining the piles' bearing capacity can be rewritten as by (19): 


$$
F_{d}^{\prime}=\gamma_{c}\left(\gamma_{R, R} \cdot \gamma_{e q 1} \cdot R \cdot A+u \cdot \sum \gamma_{R, f} \cdot \gamma_{e q 2} \cdot f_{i} \cdot h_{i}-P_{n}\right)
$$

\subsubsection{According to Vietnamese normative documents}

Due to the lack of guidance on taking into account the influence of soil liquefaction on the bearing capacity of piles, with a similar approach to determining the bearing capacity of piles, which is set out in SP 24.13330.2011, the value of the negative load is calculated by the formula (20):

$$
P_{n}=u \sum_{0}^{h_{d}} f_{i} l_{i}
$$

where $f_{i}$ - unit negative frictional resistance, defined by (21):

$$
f_{i}=\varsigma \sigma_{z g} \tan \varphi_{I}+c_{I}
$$

The value of $\varsigma$ shall be defined by (18). The formula for determining the piles' bearing capacity, taking into account the influence of soil liquefaction has been rewritten as (22):

$$
R_{c, u}^{\prime}=\gamma_{c}\left(\gamma_{c q} \cdot \gamma_{e q 1} \cdot q_{b} \cdot A_{b}+u \cdot \sum \gamma_{c f} \cdot \gamma_{e q 2} \cdot f_{i} \cdot l_{i}-P_{n}\right)
$$

\subsubsection{According to Eurocodes}

According to the proposed hypothesis, it is assumed that negative friction occurs within the thickness of the liquefied soils. In the absence of detailed instructions for determining the maximum value of negative friction, it is proposed to define negative friction as positive skin friction of the pile, but with a minus sign.

\subsubsection{According to American normative documents}

According to clause 3.1.8 [19], sandy and clayey soil liquefaction can cause negative skin loads effecting on the piles. The value of these negative frictions is determined using $\alpha$-method for cohesive soils and $\beta$-method for cohesionless soils. As in determining positive frictions, negative frictions are not taken into account within $1.5 \mathrm{~m}$ from the pile head.

\section{Results and discussion}

As an example for the bearing capacity's calculations, a pile foundation of 4 bored piles with a diameter of $d=1.5 \mathrm{~m}$ and a length of $l=40 \mathrm{~m}$ is considered. The cross-sectional area of the pile is $A=1.766 \mathrm{~m}^{2}$; cross-sectional perimeter is $u=4.71 \mathrm{~m}$. The group effect between the piles is neglected. The considered area in this example has a magnitude of 8.0. The work of the pile foundation is considered under the geological conditions of Ho Chi Minh City.

Based on the results of boring and analysis, the ground includes the following layers: 1 clayey silt, 2B - sandy clay, 3A and 3B - clay sand, 4 - sandy clay. The piles are supported on layer 4. The physical-mechanical properties of soil layers along the length of piles are presented in table 1 . 
Table 1. Physical-mechanical properties of soil layers in Ho Chi Minh City.

\begin{tabular}{|c|c|c|c|c|c|c|}
\hline Properties & Layer 1 & $\begin{array}{c}\text { Layer } \\
\text { 2B }\end{array}$ & $\begin{array}{c}\text { Layer } \\
3 \mathrm{~A}\end{array}$ & Layer 4 & $\begin{array}{c}\text { Layer } \\
3 \mathrm{~A}\end{array}$ & $\begin{array}{c}\text { Layer } \\
3 \mathrm{~B}\end{array}$ \\
\hline Thickness, $\mathrm{m}$ & 18.7 & 8.6 & 8.4 & 6.5 & 7.8 & 10 \\
\hline$N_{S P T}$ & 0 & $9-22$ & $13-35$ & $18-34$ & $13-35$ & $28-51$ \\
\hline $\begin{array}{c}\text { Specific weight } \gamma, \\
\mathrm{kN} / \mathrm{m}^{3}\end{array}$ & 15 & 19.6 & 19.5 & 19.9 & 19.5 & 19.9 \\
\hline $\begin{array}{c}\text { Specific weight of soil } \\
\text { particles } \gamma_{s}, \mathrm{kN} / \mathrm{m}^{3}\end{array}$ & 26.1 & 26.9 & 26.7 & 26.8 & 26.7 & 26.6 \\
\hline Flow index, $I_{L}$ & 1.26 & 0.31 & 0.36 & 0.25 & 0.36 & 0.18 \\
\hline $\begin{array}{c}\text { Plastic index } I_{P}, \% \\
\text { Air void ratio, e }\end{array}$ & 31.9 & 15.3 & 5.8 & 11.2 & 5.8 & 5.5 \\
\hline $\begin{array}{c}\text { Degree of water } \\
\text { saturation, } \mathrm{S}_{\mathrm{r}}\end{array}$ & 98 & 94 & 81 & 93 & 81 & 81 \\
\hline Cohesion c, $\mathrm{kPa}$ & 9 & 18.7 & 10.5 & 9.9 & 10.5 & 11.9 \\
\hline Friction angle $\varphi$, deg. & 3 & 18 & 23 & 25 & 23 & 24 \\
\hline $\begin{array}{c}\text { Undrained shear strength } \\
c_{u}, \mathrm{kPa}\end{array}$ & 26.3 & 69.6 & 81.6 & 65.1 & 76.5 & 71.7 \\
\hline
\end{tabular}

\subsection{Results of calculations without taking into account the soil liquefaction}

According to Russian documents: the bearing capacity is defined by the formula (1). By the formula (3) have found $\alpha_{\varepsilon}=0.214 \mathrm{~m}^{-1}$. For the calculation, the maximum value of the depth $h_{d}$ is taken: $h_{d}=3 / \alpha_{\varepsilon}=14 \mathrm{~m}$. According to SP 24.13330 .2011 and by a number of calculations have found the following values: $R=3250 \mathrm{kPa}, \gamma_{c}=1, \gamma_{R, R}=1, \gamma_{e q 1}=0.8$, $\sum \gamma_{R, f} \cdot \gamma_{e q 2} \cdot f_{i} \cdot h_{i}=573.53 \mathrm{kN} / \mathrm{m}$. By substituting these values into the formula (1), the pile's bearing capacity is obtained: $F_{d}=7293 \mathrm{kN}$.

According to Vietnamese documents: the deformation coefficient is $\alpha_{\varepsilon}=0.266 \mathrm{~m}^{-1}$, the maximum value of the depth $h_{d}=3 / \alpha_{\varepsilon}=11.3 \mathrm{~m}$. According to TCVN 10304:2014 and by a number of calculations have found: $q_{b}=3250 \mathrm{kPa}, \gamma_{c}=1, \gamma_{c q}=1, \quad \gamma_{\text {eq } 1}=0.8$, $\sum \gamma_{c f} \cdot \gamma_{e q 2} \cdot f_{i} \cdot l_{i}=574.12 \mathrm{kN} / \mathrm{m}$. Wherein the bearing capacity of the pile: $R_{c, u}=7295.7$ $\mathrm{kN}$.

Many studies traditionally consider the thickness of the soil layer to a depth of 15-20 m from the earth's surface to assess liquefaction. In case of insufficient geological data in the volume of exploration executed, for calculations according to Eurocodes and American normative documents, it is believed that within $20 \mathrm{~m}$ from the earth's surface, there may be losses in the bearing capacity of soils due to liquefaction, i.e. $h_{d}=20 \mathrm{~m}$.

According to Eurocodes: calculations are performed following the formula (7) for DA1, DA-2 and DA-3. Based on the geological exploration data and the methods described in clause 2.1.3, the following values are determined $R_{b, k}=1034.7 \mathrm{kN} R_{s, k}=4172.88 \mathrm{kN}$.

By approach DA-1:

- $\quad$ By combination 1: $\gamma_{b}=1.25, \gamma_{s}=1.0, R_{c, d}=4762.5 \mathrm{kN}$. 
- By combination 2: $\gamma_{b}=1.6, \gamma_{s}=1.3, R_{c, d}=3673 \mathrm{kN}$.

By approach DA-2: $\gamma_{b}=1.1, \gamma_{s}=1.1, R_{c, d}=4508.7 \mathrm{kN}$.

By approach DA-3: $\gamma_{c u}=1.4, \gamma_{b}=1.0, \gamma_{b}=1.0, R_{c, d}=3542.6 \mathrm{kN}$.

According to American documents: resistance factors are taken equal to $\varphi_{q p}=1$, $\varphi_{q s}=1$. The unit tip resistance is determined by the formula (12): $q_{p}=585.9 \mathrm{kPa}$. The unit side resistance for each soil layer is, accordingly: $q_{s, 2 B}=38.28 \mathrm{kPa}, q_{s, 3 A}=44.88 \mathrm{kPa}$, $q_{s, 4}=35.81 \mathrm{kPa}$. In this case the bearing capacity of pile is equal to $R_{R}=4851.8 \mathrm{kN}$.

\subsection{Results of calculations taking into account the soil liquefaction}

According to Russian documents: the negative additional friction manifests itself within the depth $h_{d}=14 \mathrm{~m}$. The value of $P_{n}$ is determined by the formula (17) and equal to $P_{n}=624.2 \mathrm{kN}$. Then, according to formula (19) the bearing capacity of the pile taking into account the influence of soil liquefaction is equal to: $F_{d}^{\prime}=F_{d}-P_{n}=7293-624.2=6668.8$ KN.

According to Vietnamese documents: the negative additional friction manifests itself within the depth $h_{d}=11.3 \mathrm{~m}$. The value of $P_{n}$ is determined by the formula (20): $P_{n}=501.4 \mathrm{kN}$. Following the formula (22): $R_{c, u}^{\prime}=R_{c, u}-P_{n}=7295.7-501.4=6794.3 \mathrm{\kappa N}$.

According to Eurocodes: the value of negative friction within $20 \mathrm{~m}$ is determined by methods as positive friction: $R_{s, k}^{\prime}=2445.76 \mathrm{kN}$. The value of the pile's bearing capacity is also estimated by the formula (5) with the subtraction of the negative friction value.

By approach DA-1:

- By combination 1: $\gamma_{b}=1.25, \gamma_{s}=1.0, R_{c, d}^{\prime}=2433.2 \mathrm{kN}$.

- By combination 2: $\gamma_{b}=1.6, \gamma_{s}=1.3, R_{c, d}^{\prime}=1881.2 \mathrm{kN}$.

By approach DA-2: $\gamma_{b}=1.1, \gamma_{b}=1.1, R_{c, d}^{\prime}=2391.2 \mathrm{kN}$.

By approach DA-3: $\gamma_{c u}=1.4, \gamma_{b}=1.0, \gamma_{s}=1.0 . R_{c, d}^{\prime}=1878.8 \mathrm{kN}$.

According to American documents: the negative additional friction appears within 20 $\mathrm{m}$, the value of which, by a number of calculations, is $R_{s}^{\prime}=1406.6 \mathrm{kN}$. The bearing capacity is equal to $R_{R}^{\prime}=R_{R}-R_{s}^{\prime}=4851.8-1406.6=3445.2 \mathrm{kN}$. 


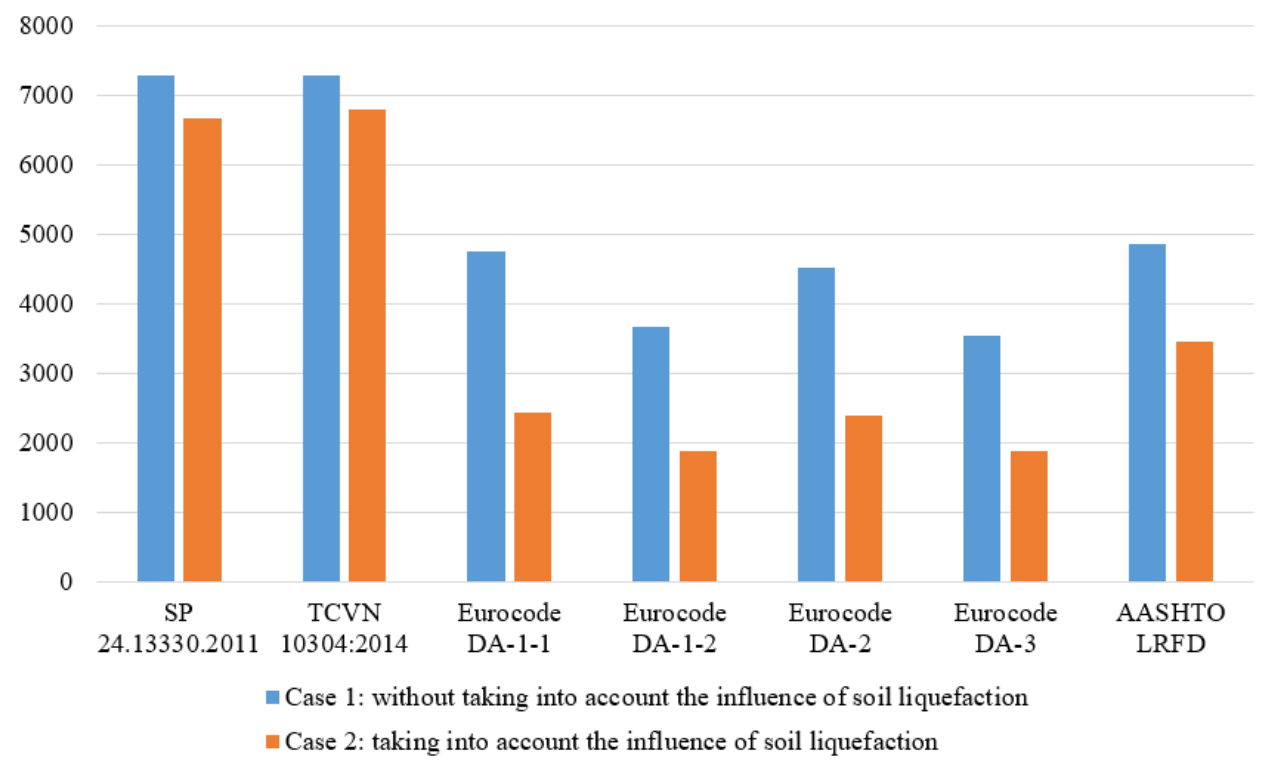

Fig. 1. Comparison of the results of calculations according to various normative documents in 2 different cases under the geological conditions of Ho Chi Minh City.

Table 2. Percentage changes in the value of the pile's bearing capacity.

\begin{tabular}{|c|c|c|c|}
\hline \multirow[b]{2}{*}{$\begin{array}{l}\text { Normative } \\
\text { document }\end{array}$} & \multicolumn{2}{|c|}{ The bearing capacity of pile in } & \multirow[b]{2}{*}{ Percentage changes } \\
\hline & $\begin{array}{c}\text { case } 1: \text { without } \\
\text { taking into account } \\
\text { the soil liquefaction }\end{array}$ & $\begin{array}{l}\text { case } 2 \text { : with taking } \\
\text { into account the soil } \\
\text { liquefaction }\end{array}$ & \\
\hline SP 24.13330.2011 & 7290.3 & 6668.8 & $9.0 \%$ \\
\hline TCVN 10304:2014 & 7295.7 & 6794.3 & $7.0 \%$ \\
\hline $\begin{array}{c}\text { Eurocode, DA-1, } \\
\text { Combination } 1\end{array}$ & 4762.5 & 2433.2 & $48.9 \%$ \\
\hline $\begin{array}{c}\text { Eurocode, DA-1, } \\
\text { Combination } 2\end{array}$ & 3673.0 & 1881.2 & $48.8 \%$ \\
\hline Eurocode, DA-2 & 4508.7 & 2391.2 & $47.0 \%$ \\
\hline Eurocode, DA-3 & 3542.6 & 1878.8 & $47.0 \%$ \\
\hline AASHTO LRFD & 4851.8 & 3445.2 & $29.0 \%$ \\
\hline
\end{tabular}

In the considering example, the value of the pile's bearing capacity according to SP 24.13330.2011 and TCVN 10304:2014 is the highest $(7293 \mathrm{kN}$ and $7295.7 \mathrm{kN}$, accordingly), and the smallest value was obtained according to Eurocode, approach DA-3 $(3542.6 \mathrm{kN})$. When considering the influence of soil liquefaction in the calculation, a significant decrease in the value of the bearing capacity is observed - by $9 \%, 7 \%, 47 \%$ $48.9 \%-48.8 \%$ and $29 \%$ in comparison with the results of the calculation without taking into account the soil liquefaction, accordingly following SP 24.13330.2011, TCVN 10304:2014, Eurocodes and AASHTO LRFD BRIDGE 2017.

\section{Conclusions}

The application of the normative document depends on the initial design requirements and geological conditions, and there is no absolutely optimal normative methodology. The 
result of this study shows specific differences in the calculation results, which is important when choosing and using one of these normative documents for the design of pile foundations under dynamic and seismic influences.

Calculations have shown that the soil liquefaction can cause significant losses in the bearing capacity of the pile. As a result of this loss, additional settlement of foundations may be observed during the operation of buildings and structures after the passage of an earthquake.

\section{References}

1. L.R. Stavnitser, Earthquake resistance of foundations (ASV Pul., Moscow, 2010).

2. X. Luo, Y. Murono, S. Tanamura. Quart. Repts. Railway Techn. Res. Inst. 3, 136-142 (2001).

3. S.P.G. Madabhushi, J.A. Knappett and S.K. Haigh, Design of pile foundation in liquefiable soils (London: Imperial College Press, 2010).

4. Y.K. Chaloulos, A. Giannakou, V. Drosos, P. Tasiopoulou, J. Chacko, S. de Wit, Soil Dynamics and Earthquake Eng. 129, 105880 (2020).

5. A. Ter-Martirosyan, A. Othman, E3S Web of Conf. 97, 03025 (2019).

6. T.G. Konstantinova, Engineering surveys 13, 28-33 (2015).

7. E.A. Voznesenskiy, E.S. Kushnareva, Engineering geology 2, 11-23 (2012).

8. H.B. Seed, K. Tokimatsu, L.F. Harder, R. Chung, Journal of Geotechnical Engineering., ASCE 121, No. 12, 856-869 (1985).

9. H.B. Seed, K.L. Lee, Journal of the Soil Mechanics and Foundations Division, ASCE 92, No. SM6, 105-134 (1966).

10. P.K. Robertson, R.G. Campanella, Journal of Geotechnical Engineering, ASCE 111, No. 3, 384-403 (1985).

11. R.W. Boulanger, I.M. Idriss, CPT and SPT based liquefaction triggering procedures, (University of california at davis, 2014).

12. B. Ghosh, J. Mian, Z. Lubkowski, 15th World Conf. on Earthquake Eng. 28, 2274622755 (2012).

13. A.Z. Ter-Martirosyan, D.A. Le, A.V. Manukyan, Vestnik MGSU 15(5), 655-664 (2020).

14. A. Ter-Martirosyan and D.A. Le, IOP Conf. Ser.: Mater. Sci. Eng. 869052025 (2020).

15. SP 24.13330.2011. Pile foundations (2019).

16. SP 14.13330.2018. Seismic Building Design Code (2018).

17. TCVN 10304:2014. Pile foundation - Design Standard (2014).

18. TCVN 9386:2012. Design of structures for earthquake resistances (2012).

19. AASHTO LRFD Bridge Design Specifications, 8th Edition (2017).

20. Eurocode 7: Geotechnical design - Part 1. EN 1997-1:2004

21. Eurocode 8: Design of structures for earthquake resistance - Part 1. EN 1998-1:2004

22. Eurocode 8: Design of structures for earthquake resistance - Part 5. EN 1998-5:2004 